\title{
Correction to: COVID-19 coronavirus: recommended personal protective equipment for the orthopaedic and trauma surgeon
}

\author{
Michael T. Hirschmann ${ }^{1,2} \cdot$ Alister Hart $^{3} \cdot$ Johann Henckel $^{3} \cdot$ Patrick Sadoghi $^{4} \cdot$ Romain Seil $^{5,6} \cdot$ Caroline Mouton $^{5}$
}

Published online: 12 June 2020

(c) European Society of Sports Traumatology, Knee Surgery, Arthroscopy (ESSKA) 2020

\section{Correction to: \\ Knee Surgery, Sports Traumatology, Arthroscopy (2020) 28:1690-1698 \\ https://doi.org/10.1007/s00167-020-06022-4}

The article COVID-19 coronavirus: recommended personal protective equipment for the orthopaedic and trauma surgeon, written by Michael T. Hirschmann, Alister Hart, Johann Henckel, Patrick Sadoghi, Romain Seil, Caroline Mouton, was originally published electronically on the publisher's internet portal (currently SpringerLink) on 27 April 2020 with open access. With the author(s)' decision to step back from Open Choice, the copyright of the article changed on 15 June 2020 to (C) European Society of Sports Traumatology, Knee Surgery, Arthroscopy (ESSKA) 2020 and the article is forthwith distributed under the terms of copyright.

The original article has been corrected.

Publisher's Note Springer Nature remains neutral with regard to jurisdictional claims in published maps and institutional affiliations.
The original article can be found online at https://doi.org/10.1007/ s00167-020-06022-4.

Michael T. Hirschmann

Michael.Hirschmann@unibas.ch

1 Department of Orthopaedic Surgery and Traumatology, Kantonsspital Baselland (BruderholzLiestalLaufen), 4101 Bruderholz, Switzerland

2 University of Basel, 4051 Basel, Switzerland

3 UCL Stanmore Campus, Royal National Orthopaedic Hospital Brockley Hill, Stanmore, UK

4 Department of Orthopedics and Trauma, Medical University of Graz, Auenbruggerplatz 5, 8036 Graz, Austria

5 Department of Orthopaedic Surgery, Centre Hospitalier de Luxembourg-Clinique d'Eich, 78 Rue d'Eich, 1460 Luxembourg, Luxembourg

6 Luxembourg Institute of Health, 78 Rue d'Eich, 1460 Luxembourg, Luxembourg 